\title{
Defect Reduction in Special Wire Mesh Production by Six Sigma Technique
}

\author{
Kritnicha Wasurattanapat ${ }^{1}$ and Rungchat Chompu-inwai ${ }^{2+}$ \\ ${ }^{1}$ Master's Degree Program in Industrial Engineering, Faculty of Engineering, Chiang Mai University, \\ Chiang Mai, Thailand \\ ${ }^{2}$ Department of Industrial Engineering, Faculty of Engineering, Chiang Mai University, Chiang Mai, \\ Thailand
}

\begin{abstract}
This research applied the Six Sigma Technique to reduce defects arising in Special Wire Mesh production processes at the case study company. Research procedure is according to the DMAIC Process. The first Define Phase identified the scope of the problem using the Flow Process Chart and Pareto Diagram to discover defect types causing the greatest damage. The second phase is the Measure Phase, which aimed at measuring capabilities of the process and conducting Measurement System Analysis by analyzing Attribute Gauge R\&R. The next phase is the Analyze Phase which analyzed the cause of the problem by brainstorming with the relevant personnel, creating a fishbone diagram and a Cause and Effect Matrix to find the causes of the type A defect. The next phase is the Improve Phase which amended the process with the principle of Visual Control. The final phase was the Control Phase. The research found it was possible to reduce the type A defect from $0.79 \mathrm{~kg} / 1,000 \mathrm{~m}^{2}$ to $0.37 \mathrm{~kg} / 1,000 \mathrm{~m}^{2}$, or a reduction of $52.58 \%$.
\end{abstract}

Keywords: six sigma technique, DMAIC process, defect reduction.

\section{Introduction}

The wire mesh industry is currently highly competitive and this is becoming more severe daily. To increase market competitiveness and increase profits, the company must apply techniques such as the Six Sigma Technique and the Lean Manufacturing Technique to reduce production costs and increase product quality to create customer satisfaction.

The case study company manufactures woven wire mesh for use in other products such as an electrode separator in the production of caustic soda, as an oil filter or as a sieve to refine ores. The company's process starts with winding wire on a beam which is taken to the weaving room and threaded by machine. Various settings are made on the weaving machine and test weaves are made. When these are complete, the weaving starts. The workpieces obtained are inspected for defects, and then sent to cleaning before being re-inspected for defects. Finally, the workpieces are cut to the sizes required by the customers and packed for shipping.

The company's products consist of many groups including Special Wire mesh. The Special Wire Mesh group of products have higher raw material costs, due to their specific properties. It must be imported from just one foreign supplier. Historical and current data find that Special Wire Mesh has continuously outsold other kinds of mesh. This has made Special Wire Mesh products the company's main focus, and its first priority in improving processes to reduce costs.

Studies of historical defect data in Special Wire Mesh products from October 3, 2015 to October 10, 2016 found that there were more than 20 kinds of frequent defect. Defects included type Q defect, where the

\footnotetext{
+ Corresponding author. Tel.: + 6653 944126; fax: +66 53944185.
}

E-mail address: rungchatc@ hotmail.com 
sheet is marked, type $\mathrm{F}$ defect, which is a stretched warp thread, and type $\mathrm{C}$ defect in which the warp thread is broken. Examples of defects in Special Wire Mesh work pieces are shown in Fig 1.

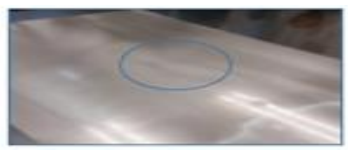

Type Q defect

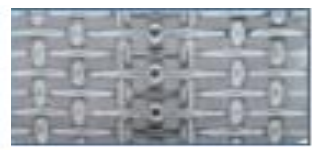

Type F defect

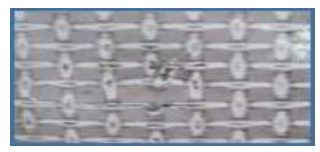

Type C defect

Fig. 1: Examples of each category of defect occurring in Special Wire Mesh work pieces.

The Six Sigma Technique is a tool for organizations to improve the capability of their business processes to help improve performance and lower variance, leading to reduced defects and improved profits, employee morale and product or service quality [1-2]. Past studies have found that the Six Sigma Technique can be applied to many industries. For example, study [3] made adjustments to reduce defect and reworks in automotive seat manufacturing using the Six Sigma Technique. The type research was able to reduce the occurrence of work pieces with holes of more than $10 \mathrm{~mm}$ by $58.12 \%$, enabling a reduction in average monthly costs of up to $\$ 390$. Study [4] reduced the rate of defects in Flex Suspension Assembly (FSA) from $2.83 \%$ to $0.66 \%$, which reduced monthly expenses from $\$ 39,195$ to $\$ 9,276$.

This research then used the Six Sigma Technique to reduce defects in the production of Special Wire Mesh at the case study company.

\section{Research Methodology and Results}

This research implemented the DMAIC Process, an initialisation of Define, Measure, Analyze, Improve and Control. The DMAIC Process need not be used solely in Six Sigma but can also be used as a guideline in solving other problems as well. Each phase of the DMAIC Process used various tools with details of research methods and results as follows:

\subsection{Define Phase}

This phase specifies the scope of the problem by considering problems arising at present and then choosing to solve the problem which does the most damage. The research started with studying the Flow Process Chart which leads to analysis to improve efficiency of working [5]. The Flow Process Chart uses the symbols of the American Society of Mechanical Engineers [6].

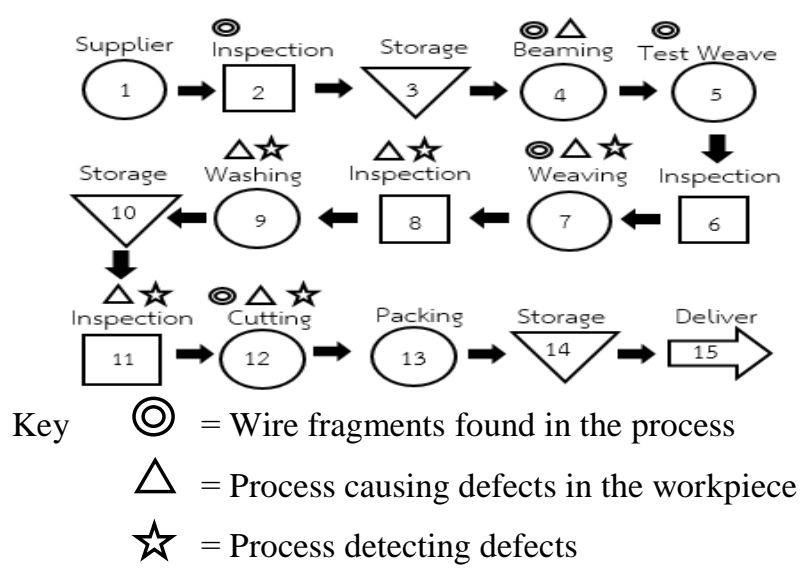

Fig. 2: Flow process chart for weaving Special Wire Mesh.

From the Flow Process Chart of weaving Special Wire Mesh as shown in Fig. 2 found that the processes causing defects in the workpiece were Process 4 (Beaming), Process 7 (Weaving), Process 8 (Inspection after waving), Process 9 (Washing), Process 11 (Inspection after washing) and Process 12 (Cutting). When defects have occurred, it is possible to inspect for defects during that process, with the exception of Process 4 (Beaming) where defects occur but cannot be found immediately. They are inspected for afterwards. Finally, processes where wire fragments were found in the process were Process 2 (Inspection after receiving 
incoming material from supplier), Process 4 (Beaming), Process 5 (Test Weave), Process 7 (Weaving) and Process 12 (Cutting).

The researchers then collected data on volumes of material damaged through each category of defect in kilogram (kg), from October 3, 2015 to October 10, 2016. The research found more than 20 kinds of defects wasting a total of $1,791.02 \mathrm{~kg}$. This data was used to create a Pareto diagram to prioritize defects as shown in Fig. 3.

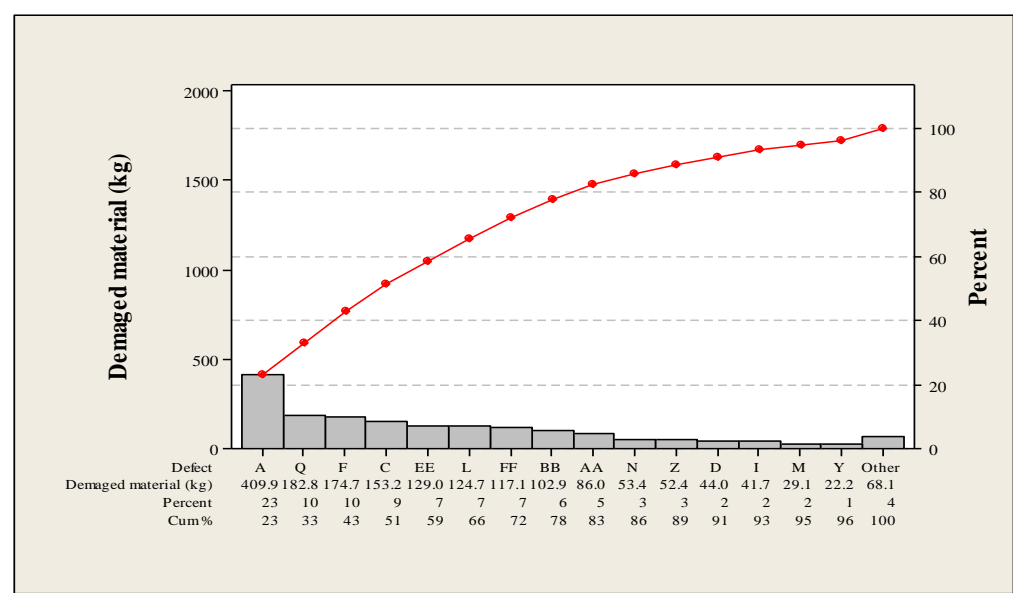

Fig. 3: Pareto diagram showing volumes of each defect occurring (kg).

From Fig. 3 it is found that the type A defect has the highest volume of $409.92 \mathrm{~kg}$ or $23 \%$ of the total. Type A defect is a defect occurring from not cutting the workpiece according to the specified length, causing the company to lose some parts of the workpiece. This research paper will explain only the methods to reduce this particular category of defect.

However, Pareto's 80/20 Rule found that the type Q, F, C, EE, L, FF, BB and AA defects had an accumulated total volume of $83 \%$. Therefore, these defects are the "Vital Few" of the few defects causing a large amount of damage [7]. There will be improvements to reduce this group of defects in future research.

\subsection{Measure Phase}

This phase is that of measuring the processes' current capability. It was found that current processes caused the type A defect at an average rate of $0.79 \mathrm{~kg} / 1,000 \mathrm{~m}^{2}$.

In addition, researchers conducted a Measurement System Analysis by analysing Attribute Gauge R\&R to analyze employees' ability to distinguish defects. The analysis started from preparing a total of 20 workpieces with equal amounts being defective and non-defective. Two employees then inspected the work pieces for defects, written as G (Good) / NG (No Good). Each employee then repeated the measurements [6]. Analysis with the Minitab program had the results shown in Tables 1-3. From Table 1 it is found that $\%$ appraiser scores of employee 1 and employee 2 had values of $100 \%$ and $95 \%$ respectively which were more than $80 \%$, showing this had passed the criteria [8]. Considering Table 2, it was found that the \%screen effective score was equal to 95\%, showing that in getting the employees to inspect 20 pieces, there were 19 pieces for which the employees' inspections had the same result, where the value obtained was more than $80 \%$, showing that these also passed the criteria [8]. The value for both employees had a 95\% Confidence Interval (CI) equal to 75.13-99.87, showing that the values were not different.

Table 1: Appraiser score

\begin{tabular}{|c|c|c|c|c|}
\hline \multicolumn{5}{|c|}{ Within Appraisers: Assessment Agreement } \\
\hline Appraiser & \# Inspected & \# Matched & $\%$ & $95 \%$ CI \\
\hline 1 & 20 & 20 & 100.00 & $(86.09,100.00)$ \\
\hline 2 & 20 & 19 & 95.00 & $(75.13,99.87)$ \\
\hline \# Matched: Appraiser agrees with him/herself across trials. \\
\hline
\end{tabular}


Table 2: Screen effective score between appraisers

\begin{tabular}{|c|c|c|c|}
\hline \multicolumn{4}{|c|}{ Between Appraisers: Assessment Agreement } \\
\hline \# Inspected & \# Matched & $\%$ & $95 \%$ CI \\
\hline 20 & 19 & 95.00 & $(75.13,99.87)$ \\
\hline \multicolumn{4}{|c|}{ \# Matched: All appraisers' assessments agree with each other. } \\
\hline
\end{tabular}

In addition, the data in Table 3 comparing employees to standard values found that the value of $95 \% \mathrm{CI}$ was 75.13-99.87, and these values were likewise not different [8].

Table 3: Screen effective score of all appraisers vs. standard

\begin{tabular}{|c|c|c|c|}
\hline \multicolumn{4}{|l|}{ All Appraisers vs Standard: Assessment Agreement } \\
\hline \# Inspected & \# Matched & $\%$ & $95 \%$ CI \\
\hline 20 & 19 & 95.00 & $(75.13,99.87)$ \\
\hline \# Matched: All appraisers' assessments agree with the known standard. \\
\hline
\end{tabular}

From Table 4 the Kappa analysis found that results from both employees had values more than or equal to 0.75 [8], meaning that inspections of both employees had very good Interrater agreement. As for repeatability of the two employees compared to standard values, this can be seen from Table 5, where the Kappa value is also more than or equal to 0.75 [8], showing good Interrater agreement.

Table 4: Results of Kappa analysis within appraisers

\begin{tabular}{|c|c|c|c|c|c|}
\hline \multicolumn{7}{|c|}{ Within Appraisers : Fleiss' Kappa Statistics } \\
\hline Appraiser & Response & Kappa & SE Kappa & Z & P(vs > 0) \\
\hline \multirow{2}{*}{1} & G & 1.00000 & 0.223607 & 4.47214 & 0.0000 \\
\cline { 2 - 6 } & NG & 1.00000 & 0.223607 & 4.47214 & 0.0000 \\
\hline \multirow{2}{*}{2} & G & 0.89975 & 0.223607 & 4.02380 & 0.0000 \\
\cline { 2 - 6 } & NG & 0.89975 & 0.223607 & 4.02380 & 0.0000 \\
\hline
\end{tabular}

Table 5: Results of Kappa analysis between appraisers

\begin{tabular}{|c|c|c|c|c|}
\hline \multicolumn{5}{|c|}{ Between Appraisers: Fleiss' Kappa Statistics } \\
\hline Response & Kappa & SE Kappa & $\mathrm{Z}$ & $\mathrm{P}(\mathrm{vs}>0)$ \\
\hline G & 0.949969 & 0.0912871 & 10.4064 & 0.0000 \\
\hline NG & 0.949969 & 0.0912871 & 10.4064 & 0.0000 \\
\hline
\end{tabular}

\subsection{Analyze Phase}

This phase is the analysis of root causes by brainstorming with the relevant personnel, comprising managers and their team members in the beaming and weaving processes. Then the team created a fishbone diagram (Fig.4) defining the problem (the occurrence of the type A defect) as the head of the fish.

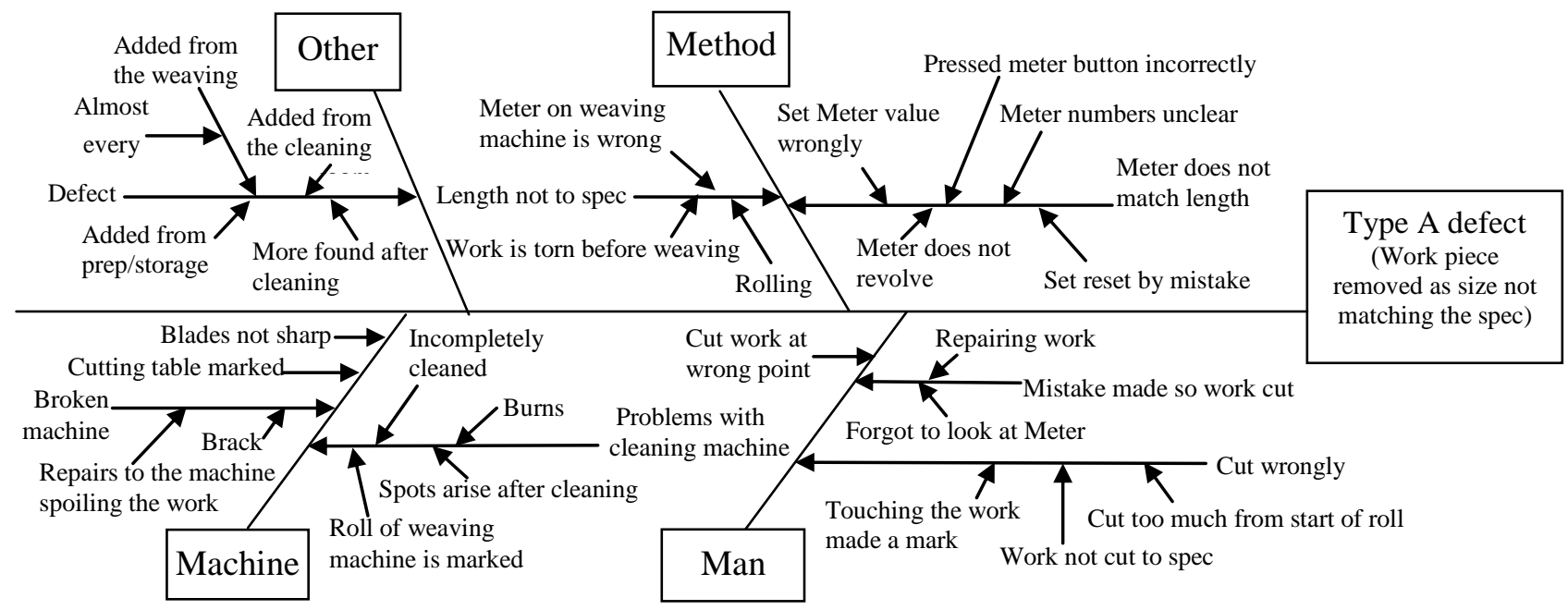

Fig. 4: Fishbone diagram showing causes of the type A defect 
Causes are divided into the 4Ms of Man, Machine, Method and Material. From there, the causes of the type A defect are prioritized, to select the causes to be further improved by creating a Cause and Effect Matrix. Appraisal is done by giving points to each cause, with two opposing criteria: (1) Feasibility of solving the problem (unsolvable $=2$ to easily solvable $=8$ ) and (2) the importance or severity of the cause (no severe impact $=2$ to very severe $=8$ ). The appraisal was done by six employees connected to the problem who had expertise in their work. The results of each appraiser were the product of the points from both criteria [9]. The appraisals were compiled as the average points from all six employees, with the causes that were the highest three overall appraised as follows:

The cause with the highest overall points at 46.67 points was "Man" with employees cutting the work wrongly or in the wrong position. This could be addressed by specifying working methods i.e. every time before cutting the sheet, the employees must measure the size of the work piece and create a clear symbol at the position to be cut.

The cause with the second highest assessment of 41.33 points was "Method". It was found that the length of the workpiece not aligning with the specification was caused by an employee applying settings to the Meter incorrectly. The Meter is equipment for making settings to the weaving machine to weave the work to the desired length. Otherwise, the employee could not specify the windings of the weaving machine. In the work, the employee brings the wire wound onto the beam to do weaving. Test weaves are done before the weaving proper. While the weaving is underway, the employee will serially cut rolls of work according to the specified sizes from the weaving machine, without clearly specifying the length of the last roll of work and how much should be woven. The problem encountered is that the last roll of work has too much length or not enough. Therefore, when it is cut into sheets, the workpiece length does not match the specification. For this reason, the researchers applied the principle of Visual Control (as explained in the next section).

As for the cause assessed overall as third with 40.00 points, this is "Man". The employee cutting the work wrongly for the specification, by not putting tools in their correct places as well as using substandard measurement tools. This can be addressed by training sessions with staff for them to understand the correct working methods and by changing measuring equipment to be a tape measure with a clear scale.

\subsection{Improve Phase}

This phase is improving processes by eliminating the causes that are the principal source of the problem (as stated earlier). This can be explained as follows. The process starts with winding enough wire onto the beam to weave 12 rolls of work pieces (one roll with a length of 78.4 meters or cut work pieces to 2.45 meters to get 32 work pieces). After that is the weaving process, which is divided into making test weaves, making tests again after a problem has been found, and making the actual weaving of rolls 1-12. The weaving starts with a test weave before the weaving proper. Meanwhile in the weaving, the weaving machine operates continuously and stops when the wire on the beam is exhausted. During the weaving, when the work pieces are woven to the length specified, the employee will serially cut rolls from the weaving machine one by one. The study found that the test weaves (each of which have unequal lengths) make the 12th (and last) roll not equal to 78.4 meters, or they cannot cut the work piece neatly according to the number of sheets, causing the type A defect. The researchers thus proposed to apply the technique of Visual Control to solve the problem.

Visual Control is a control system for working which enables every employee to easily and clearly understand the work process, targets and the results of working. This includes observing various irregularities and dealing with them quickly. It uses boards, signs with symbols, graphs and colors, etc. to communicate important information to staff and all other relevant personnel [10]. The researchers proposed to create a sign showing the values of various numbers which are easy to see, as shown in Fig. 5, for staff to have the same understanding about setting the Meter on the weaving machine. 

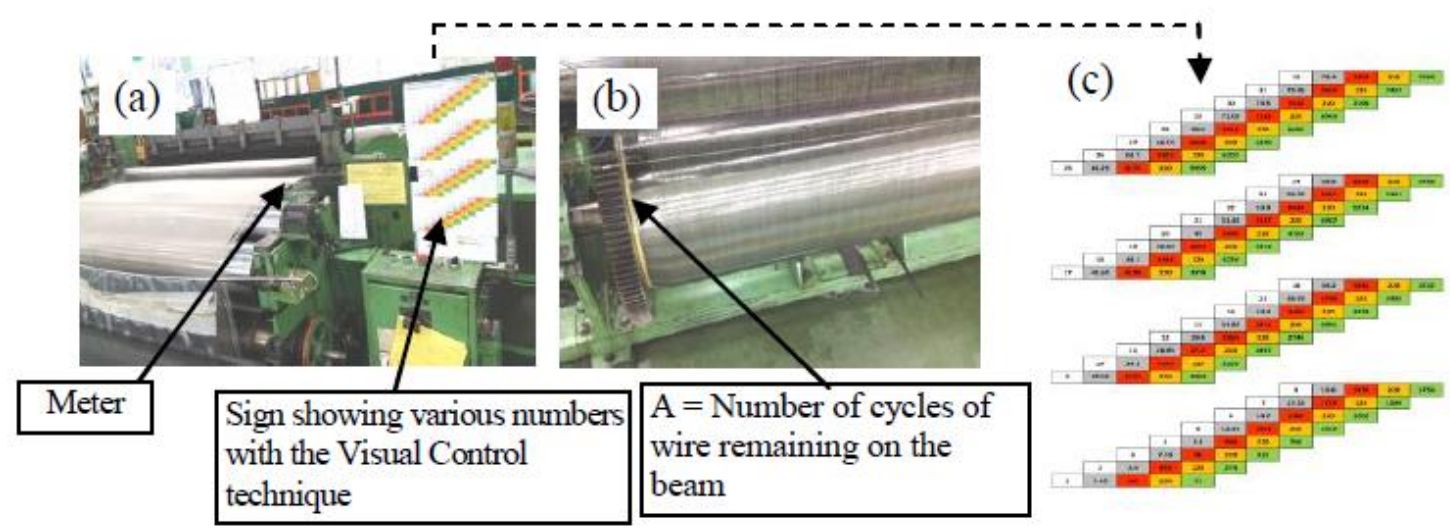

Fig. 5: Reducing type A defect with the principle of Visual Control: (a) Front of the weaving machine (b) The beam which is behind the weaving machine and (c) sign showing various numbers.

Details of various values as shown on the sign in Fig. 5(c) with details as shown in Fig. 6.

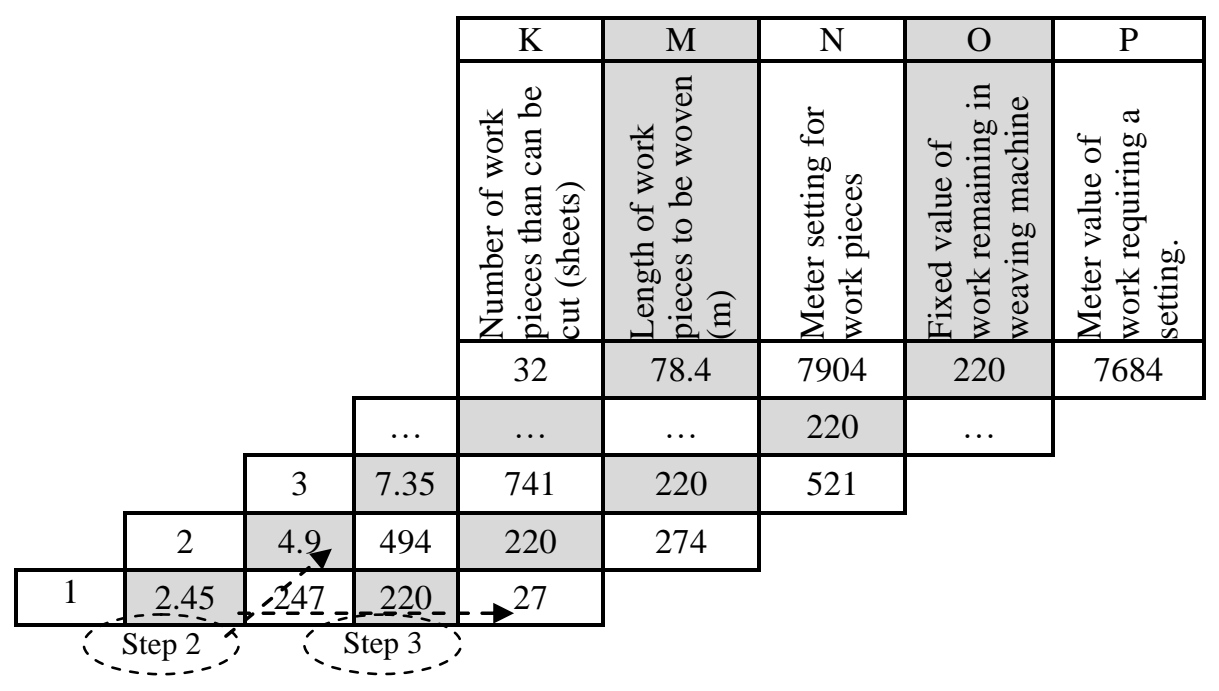

Fig. 6: Example of detail on the sign from the principle of vision control.

From Fig. 6 the details of operation are as follows:

1. From Fig. 5(b), the operator reads the value A (remaining windings of wire left on the beam) and calculates the length of the workpiece that can be woven (meters) (specified as the symbol B) from the equation $\mathrm{B}=\mathrm{A} \times 1.25$

2. Then use the value $B$ obtained to select the value $M$ in Fig. 6. For example, if $B=4$, when $M$ is read, and it is found to be between 2.45 and 4.9 , then select $M=2.45$ for the workpiece to be cut neatly into sheets.

3. In Fig. 6, from the value $M$, the operator reads the right-hand value at P. For example, when reading $\mathrm{M}=2.45$, then look to the right to get $\mathrm{P}=27$, and so set the Meter of the weaving machine (in Fig. 5(a)) to 27.

4. The operator measures the length of the last roll and calculates the amount of the remainder from the cut in units of $\mathrm{kg} / 1,000 \mathrm{~m}^{2}$

Table 6: Results of improvement to reduce type A defect

\begin{tabular}{|c|c|c|c|c|c|}
\hline $\begin{array}{c}\text { Type A } \\
\text { defect }\end{array}$ & $\begin{array}{c}\text { Average total } \\
\text { woven area }\left(\mathrm{m}^{2}\right)\end{array}$ & $\begin{array}{c}\text { Average length } \\
\text { of last roll }(\mathrm{m})\end{array}$ & $\begin{array}{c}\text { Average work pieces } \\
\text { obtained (sheets) }\end{array}$ & $\begin{array}{c}\text { Average } \\
\text { remainder } \\
(\mathrm{kg})\end{array}$ & $\begin{array}{c}\text { Average Defects } \\
\text { occurring }(\mathrm{kg} / 1,000 \\
\left.\mathrm{m}^{2}\right)\end{array}$ \\
\hline Before & 1076.10 & 61.94 & 25.28 & 0.85 & 0.79 \\
\hline After & 1112.93 & 67.45 & 27.53 & 0.41 & 0.37 \\
\hline
\end{tabular}


When testing the proposed improvements, it was found that type A defect could be reduced from an average of $0.79 \mathrm{~kg} / 1,000 \mathrm{~m}^{2}$ to an average of $0.37 \mathrm{~kg} / 1,000 \mathrm{~m}^{2}$ as shown in Table 6.

\subsection{Control Phase}

Once it was found that the improvements were actually able to reduce occurrence of the type A defect, this stage is maintaining the improvement. Standard operating procedures for machine operators were created, for confidence that the results of this project will be used to improve the company's operations.

\section{Conclusion and Discussion}

This study applied the Six Sigma Technique to reduce type A defect occurring in Special Wire Mesh Production of the case study company. The DMAIC Process was followed and the process improved with Visual Control. The study concluded that it was possible to reduce type A defect from $0.79 \mathrm{~kg} / 1,000 \mathrm{~m}^{2}$ to $0.37 \mathrm{~kg} / 1,000 \mathrm{~m}^{2}$, a reduction of $52.58 \%$. Besides this, the case study company was able to use the data collected on this occasion to specify preparations for the length of wire on the beam in the beam room. If the company prepared a wire length that was too little or too much, when it was taken to weave work pieces, they could not be cut to size as specified.

As for future research, there may be improvements to eliminate causes which received the next level of points from appraisals prioritizing the causes. For instance, in the "Machine" causes, it was found that one cause of type A defect was that the blades cutting the work pieces were not sharp from their incessant use. Therefore, there should be a work cycle specified for the blades and standards to check the sharpness of the blades, as well as specifying maintenance for all tools.

Besides this, in compiling the data, it was found that other categories of defects also caused the type A defect, as any defect which had occurred required cutting parts from work pieces. Therefore, the number of sheets is not obtained as specified. Thus, future research might do improvements to reduce other defects in the "Vital Few" uncovered from analysis of the Pareto Diagram. For instance, the type Q defect in the weaving process could be reduced by using the Poka-Yoke principle, which would prevent unintentional errors.

\section{Acknowledgment}

The authors would like to acknowledge the cooperation of the case study company and its employees. Moreover, the authors gratefully acknowledge the financial support provided for the research by the Research and Researcher for Industry (RRI) fund 2017, a part of the Thailand Research Fund (TRF).

\section{References}

[1] J. Cherry, and S. Seshadri. Six Sigma: Using Statistics to Reduce Process variability and Cost in Radiology. Radiology Management. 2000, 22(6): 42-45.

[2] T. Pyzdek, and P.A. Keller. The Six Sigma Handbook A Complete Guide for Green Belts, Black Belts, and Managers at All Levels. New York: McGraw-Hill Press, 2010.

[3] P. Plernpookhiew. Reduction of Defect and Reworks in Automotive Seat Manufacturing using Six Sigma Concept: Master's Thesis, Department of Engineering Management, Faculty of Engineering, Burapha University. Thailand, 2016.

[4] S. Wannarumon. Defect Reduction Using Six Sigma Technique: Master's Thesis, Department of Industrial Engineering, Faculty of Engineering, Chiang Mai University. Thailand, 2004.

[5] S. Prukpitikul. Development of Lean Six Sigma Quality. Bangkok: Technology Promotion Association (ThailandJapan) Press, 2003.

[6] K. Ploypanichcharoen. Principles of quality control. Bangkok: Technology Promotion Association (ThailandJapan) Press, 2007.

[7] S. Natapan. Quality Control. Bangkok: Se-ed Press, 2008. 
[8] K. Ploypanichcharoen. Measurement System Analysis by Minitab 15. Bangkok: Technology Promotion Association (Thailand-Japan) Press, 2010.

[9] Y. Sriwichai and R. Chompu-inwai. Reduction of Defective Products in Wire Mesh Production Using Six Sigma Technique: Master's Thesis, Department of Engineering, Faculty of Engineering, Chiang Mai University. Thailand, 2011.

[10] P. Moolla. Application of Cleaner Technology in Arm Coil Assembly Process of Hard Disk Drive Manufacturing: Master of Engineering, Department of Industrial Engineering, Faculty of Engineering, Chiang Mai University. Thailand, 2011. 